\title{
PELATIHAN GURU MATA PELAJARAN GEOGRAFI DALAM PERSIAPAN OSN GEOGRAFI DI KABUPATEN DONGGALA
}

\author{
Rahmawati $^{1}$, Iwan Alim Saputra ${ }^{2}$, Muhammad Rusli ${ }^{3}$ \\ ${ }^{1,2}$ Pendidikan Ilmu Sosial, Fakultas Keguruan dan Ilmu Pendidikan, Universitas Tadulako \\ ${ }^{3}$ Fisika, Fakultas Matematika dan Ilmu Pengetahuan Alam, Universitas Tadulako \\ thywa_03@yahoo.com ${ }^{1}$, ia14307@yahoo.com ${ }^{2}$, rusli8998@yahoo.com ${ }^{3}$
}

\begin{abstract}
ABSTRAK
Olimpiade Sains Nasional atau yang disingkat dengan OSN memiliki arti penting sebagai ajang prestasi pencapaian mutu pendidikan nasional, dan menjadi referensi bagi upaya-upaya penjaminan mutu pendidikan secara berkelanjutan. Adapun manfaat dari OSN. Pertama, memotivasi peserta didik dalam belajar ketika melihat teman-teman dan kakak-kakak kelasnya berhasil dalam OSN. Kedua, OSN sebagai benchmark antar daerah, sehingga dapat melihat sejauh mana perkembangan masing-masing daerah dalam meningkatkan mutu dan kualitas pembelajarannya. Ketiga, bila ditemukan ketidakseimbangan peraih juara antar daerah, akan menjadi bahan untuk melakukan upaya peningkatan mutu di daerah yang minim juara OSN. Oleh karena itu, program ini menjadi penting untuk dilaksanakan sebagai upaya peningkatan kompetensi guru dalam membimbing OSN geografi. Tujuan program pengabdian masyarakat ini, memberikan pelatihan serta pendampingan bagi guru mata pelajaran geografi di Kabupaten Donggala dalam membimbing siswa menghadapi OSN Geografi..
\end{abstract}

Kata Kunci: OSN, Geografi, Tips dan Trik

\begin{abstract}
The National Science Olympiad, or abbreviated as OSN, has an important meaning as a venue for achieving the quality of national education, and is a reference for efforts to ensure quality education in a sustainable manner. The benefits of OSN. First, motivating students to learn when they see their classmates and friends succeed in OSN. Second, OSN as a benchmark between regions, so that they can see the extent of the development of each region in improving the quality and quality of learning. Third, if an imbalance between championship winners is found among regions, it will be an ingredient to make efforts to improve quality in regions with minimal OSN champions. Therefore, this program becomes important to be implemented as an effort to improve teacher competence in guiding OSN geography. The aim of this community service program is to provide training and mentoring for geography subject teachers in Donggala Regency in guiding students towards Geography OSN.
\end{abstract}

Keywords: OSN, Geography, Tips and Tricks.

\section{PENDAHULUAN}

Pengembangan culture budaya yang membentuknya bisa disebabkan karena pengembangan sektor pertanian (1-3) yang berkesinambungan, sehingga dapat membentuk karakter dari siswa yang dididik. Pemerintah telah melakukan berbagai bentuk kegiatan secara terpadu dan terkoordinasi baik ditingkat sekolah, kabupaten/ kota, propinsi maupun nasional 
dan internasional untuk mengukur sejauh mana kualitas pendidikan yang didapatkan oleh peserta didik [4] Adapun bentuk-bentuk kegiatan yang dilakukan antara lain Olimpiade Sains Nasional (OSN), Lomba Penelitian Ilmiah Remaja (LPIR) serta Olimpiade Olahraga Siswa Nasional (O2SN). Olimpiade Sains Nasional atau yang disingkat dengan OSN memiliki arti penting sebagai ajang prestasi pencapaian mutu pendidikan nasional, dan menjadi referensi bagi upaya-upaya penjaminan mutu pendidikan secara berkelanjutan [5]. OSN merupakan kegiatan yang bertujuan: a) Menumbuh-kembangkan sikap kompetitif yang sehat dikalangan siswa SD/ MI, SDLB/ SD Inklusi (tunanetra/ tunarungu/ tunadaksa ringan), SMP/ MTs, dan SMA/ MA pada tingkat sekolah, kabupaten/ kota, provinsi, nasional, dan internasional; b) Menjaring siswa siswi unggul dibidang sains dan teknologi untuk dipersiapkan menjadi anggota tim nasional dalam kompetisi internasional; c) memotivasi siswa agar lebih gemar belajar sains; dan d) Memacu peningkatan mutu pendidikan khususnyadi bidang sains dan teknologi [6].

Terdapat tiga manfaat Olimpiade Sains Nasional (OSN). Pertama, memotivasi peserta didik dalam belajar ketika melihat teman-teman dan kakak-kakak kelasnya berhasil dalam OSN. Kedua, OSN sebagai benchmark antar daerah, sehingga dapat melihat sejauh mana perkembangan masing-masing daerah dalam meningkatkan mutu dan kualitas pembelajarannya. Ketiga, bila ditemukan ketidakseimbangan peraih juara antar daerah, akan menjadi bahan untuk melakukan upaya peningkatan mutu di daerah yang minim juara OSN $[5]$.

Berdasarkan penjelasan diatas, maka salah satu daerah yang minim mengikuti OSN khususnya dalam bidang geografi adalah Kabupaten Donggala. Berdasarkan hasil wawancara dengan ketua MGMP Geografi Kabupaten Donggala ibuYulita, S.Pd, diketahui bahwa hampir setiap pelaksanaan OSN, peserta didik di Kab. Donggala tidak pernah lolos seleksi untuk tingkat propinsi, selain itu minat siswa untuk mengikuti olimpiade masih sangat minim. Kedua permasalahan tersebut terjadi, karena kurangnya motivasi guru dalam menarik peserta didik untuk berkompetensi, serta tingkat penguasaan materi pembelajaran yang rendah, dikarenakan hampir sebagian besar guru yang mengajar mata pelajaran geografi berasal dari bidang keilmuan non geografi (Sejarah, Ekonomi, dan PKN). Ketidaklinearan ilmu ini mengakibatkan guru-guru geografi banyak yang tidak memberikan beberapa materi pelajaran terkait pemetaan, diantaranya kartografi, penginderaan jauh, system informasi geografi dan pengembangan wilayah. Kejadian ini terjadi akibat ketidakmampuan guru dalam 
menghitung, menggambarkan dan menjelaskan materi-materi terkait pengembangan ilmu. Olehnya peserta didik hanya mendapatkan materi-materi geografi social dikelas, dan pada kenyataannya soal-soal OSN geografi didominasi oleh materi-materi pemetaan dan pengembangan wilayah.

Permasalahan selanjutnya adalah keterampilan guru dalam menggunakan dan mengaplikasikan alat-alat pemetaan masih sangat rendah. Hal ini dikarenakan, keseluruhan sekolah SMA di daerah ini sama sekali tidak memiliki alat-alat pemetaan, baik berupa GPS, The odolith dan alat pemetaan lainnya, sehingga siswa tidak memahami bagaimana menggunakan alat-alat tersebut. Kelemahan siswa dalam penggunaan alat tidak hanya terjadi di Kabupaten ini, Kota Palu sebagai ibukota pusat propinsi dengan fasilitas Pendidikan yang baik, ternyata memiliki permasalahan yang sama, terbukti dengan kekalahan siswa OSN geografi 2017 Perwakilan Palu (SMAAl-Azhar) ditingkat nasional, salah satu factor yang menyebabkan kegagalan adalah pada sesi praktek, dimana siswa tidak dapat menggunakan the odolite. Inilah gambaran, bagaimana guru-guru geografi di Sulawesi Tengah khususnya Kabupaten Donggala yang masih sangat rendah dalam penguasaan materimateri OSN geografi serta minim penguasaan alat-alat pemetaan.

\section{METODE}

Kegiatan ini dalam pelaksanaannya menggunakan metode sosialisasi, pelatihan, pendampingan dan evaluasi, yakni memberikan pengetahuan, pemahaman dan latihan serta pendampingan guna meningkatkan kemampuan guru geografi dalam penguasaan materimateri OSN Geografi. Adapun sasaran dari kegiatan ini adalah guru-guru geografi yang tergabung di dalam MGMP Geografi Kabupaten Donggala

\section{HASIL DAN PEMBAHASAN}

Pelaksanaan kegiatan dilakukan di dua tempat yaitu di Kabupaten Donggala, SMA Negeri SMA Negeri 1 Sindue. Pengambilan lokasi kegiatan ini didasarkan pada jarak peserta ke lokasi pengabdian. Untuk satu kabupaten peserta harus menempuh jarak maksimal ke lokasi pengabdian sejauh $200 \mathrm{~km}$, sehingga pengambilan titik lokasi pengabdian diharapkan tidak memberatkan dan menurunkan motivasi peserta untuk mengikuti kegiatan pelatihan ini.

Waktu pelaksanaan kegiatan dilaksanakan dalam dua waktu yang berbeda, kegiatan pertama pelatihan dilakukan di Kabupaten Donggala selama dua hari pada tanggal 13 dan 14 
Juni. Kegiatan ini dihadiri 20 guru geografi tingkat SMA se-Kabupaten Donggala. Adapun guru geografi yang hadir berasal dari 13 Sekolah di Kabupaten Donggala, dengan rincian sebagai berikut;

Tabel 4.1 Jumlah Guru Geografi yang menghadiri pelatihan OSN di tiap sekolah SMA di Kabupaten Donggala.

\begin{tabular}{|c|l|c|}
\hline No & \multicolumn{1}{|c|}{ Nama Sekolah } & $\begin{array}{c}\text { Jumlah } \\
\text { Guru }\end{array}$ \\
\hline 1 & SMAN 1 Banawa & 2 \\
\hline 2 & $\begin{array}{l}\text { SMAN 1 Banawa } \\
\text { Tengah }\end{array}$ & 2 \\
\hline 3 & SMAN 1 Riopakava & 1 \\
\hline 4 & SMAN 1 DAMPELAS & 2 \\
\hline 5 & SMAN 2 DAMPELAS & 2 \\
\hline 6 & SMAN 1 SOJOL & 1 \\
\hline 7 & SMAN 2 SOJOL & 1 \\
\hline 8 & SMAN 1 SIRENJA & 1 \\
\hline 9 & SMAN 1 SINDUE & 2 \\
\hline 10 & $\begin{array}{l}\text { SMAN 1 } \\
\text { TOMBUSABORA }\end{array}$ & 1 \\
\hline 11 & $\begin{array}{l}\text { SMAN 1 SINDUE } \\
\text { TOBATA }\end{array}$ & 2 \\
\hline 12 & SMAN 1 SIRENJA & 1 \\
\hline 13 & $\begin{array}{l}\text { SMAN 1 BANAWA } \\
\text { SELATAN }\end{array}$ & 2 \\
\hline \multicolumn{2}{|c|}{ Total Guru } & 20 \\
\hline
\end{tabular}

Adapun pelaksanaan kegiatan pada hari pertama dimulai dengan pembukaan oleh kepala sekolah SMA 1 Sindue dan Ketua MGMP Donggala kemudian dilanjukan dengan pemberian materi model pembelajaran yang disampaikan oleh bapak Iwan Alim Saputra (Gambar 5.1 dan 5.2).

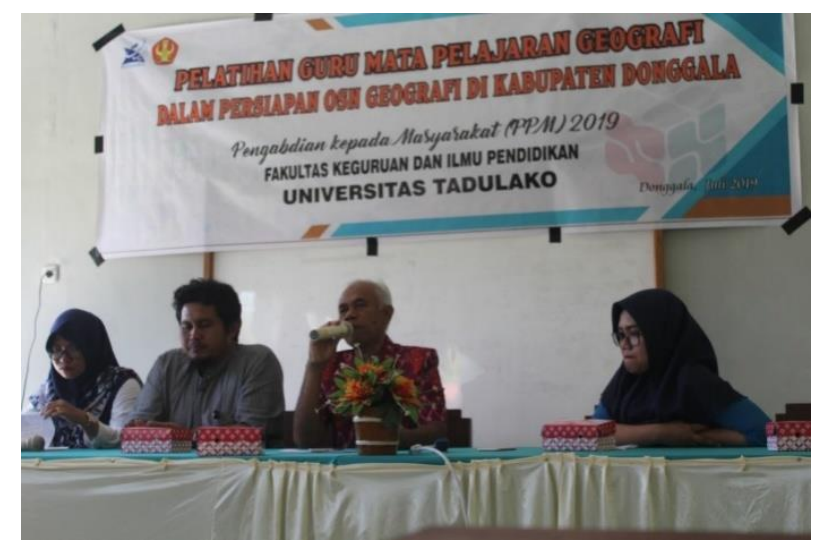

Gambar 5.1 Pembukaan Kegiatan Pelatihan Guru Mata Pelajaran Geografi dalam Persiapan OSN Geografi di Kabupaten Donggala 


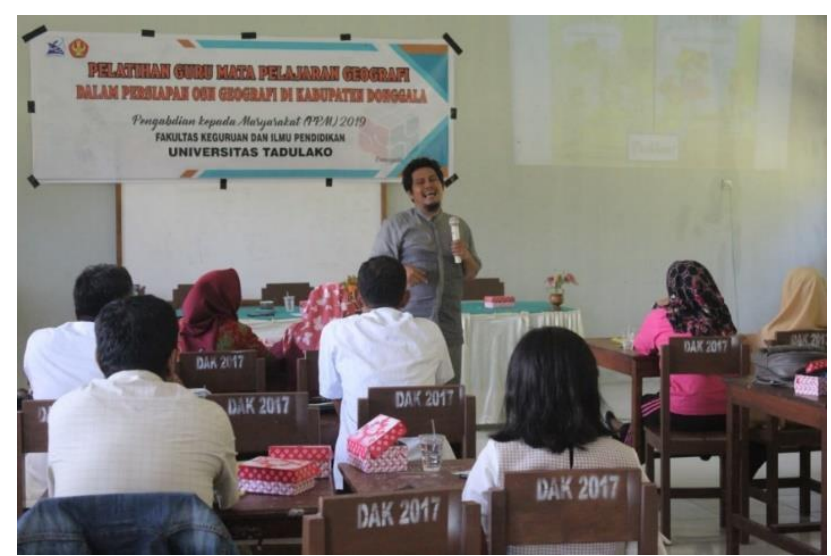

Gambar 5.2 Pemberian materi terkait model pembelajaran geografi

Materi sselanjutnya adalah pendalaman materi terkait; system informasi geografi yang dibawakan secara garis besar berisi tentang ; (1) sejarah dan konsep dasar GPS, RS dan SIG, (2) Pengenalan SIG, (3) Keunggulan SIG, (4) Karakteristik SIG, (5) Trend teknologi geoinformasi, (6) Hambatan dan tantangan perkembangan SIG di Indonesia. Pemberian materi ini dilakukan dengan durasi 3 jam. Selama proses pemberian materi, para peserta sangat antusias, beberapa pertanyaan diutarakan oleh peserta untuk memperdalam materi, sehingga waktu pemberian materi yang seharusnya 2 jam menjadi 3 jam.

Materi hari berikutnya masih terkait pendalaman materi yang dilakukan oleh bapak rendra, S.Pd, M.Pd terkait materi hidrologi selama 3 jam, selanjutnya materi selanjutnya adalah terkait tips dan trik dalam menjawab soal-soal olimpiade yang dibawakan oleh Rahmawati, S.Si., M.Sc (Gambar 5.3). materi ini sangat antusias diikuti oleh para peserta dikarenakan hampir sebagian besar guru tidak dapat menjawab tes awal yang kami berikan terkait beberapa soal-soal olimpiade.

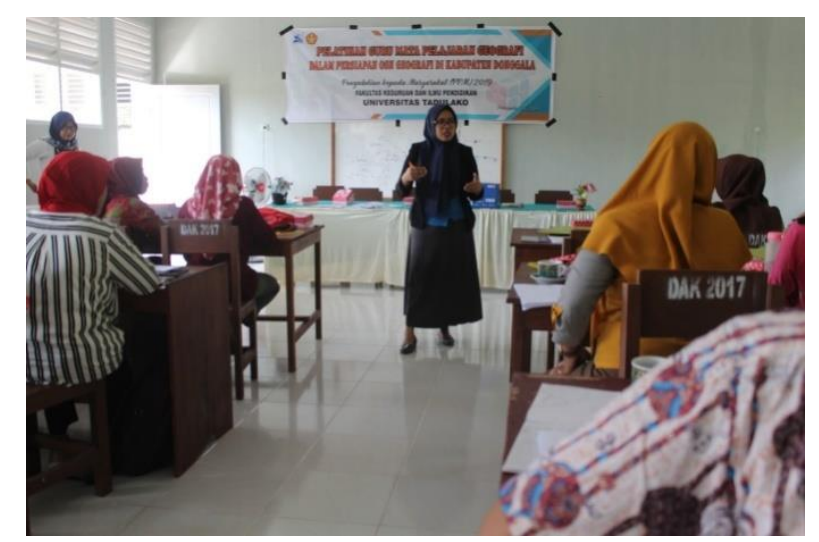

Gambar 5.3 Pemberian tips dan trik alam menjawab soal olimpiade 
Adapun tes awal yang kami berikan mencakup materi meteorology dan klimatologi, oseanografi, geologi, kartografi, Penginderaan Jauh dan Sumberdaya Alam. Hasil identifikasi diperoleh informasi awal tingkat pengetahuan guru.

Tabel 4.2 Tingkat pengetahuan guru materi geografi sebelum pelaksanaan pelatihan

\begin{tabular}{|c|l|c|}
\hline No & \multicolumn{1}{|c|}{ Materi } & Tingkat pengetahuan guru (\%) \\
\hline 1 & $\begin{array}{l}\text { Meteorologi dan } \\
\text { Klimatologi }\end{array}$ & $80 \%$ \\
\hline 2 & Oseanografi & $70 \%$ \\
\hline 3 & Geologi & $80 \%$ \\
\hline 4 & Kartografi & $40 \%$ \\
\hline 5 & Penginderaan Jauh & $55 \%$ \\
\hline 6 & Sumberdaya Alam & $75 \%$ \\
\hline
\end{tabular}

Berdasarkan hasil identifikasi awal diketahui bahwa tingkat pengetahuan guru untuk materi kartografi dan penginderaan jauh masih rendah, hal ini dikarenaka kurangnya pemahaman guru khususnya dalam menghitung nilai kontur, penentuan arah dan menghitung luasan suatu daerah. Terkhusus soal SIG dan Penginderaan Jauh (PJ), terdapat sembilan guru yang sama sekali tidak dapat menjawab soal yang diberikan. Hal ini menandakan bahwa hampir sebagian guru tidak mampu dalam mengajarkan materi perpetaan, SIG dan PJ.

Materi Selanjutnya adalah praktek penggunaan alat yang digunakan dalam pembelajaran geografi yang dilakukan oleh bapk Muhammad Rusli, S.Si.,MT. Alat yang diajarkan berupa penggunaan kompas geologi, GPS dan Theodolit. Proses pemberian ini sangat menarik, dikarenakan guru-guru geografi di Kabupaten Donggala belum pernah menggunakan dan mengajarkan materi ini ke siswa mereka, hal ini disebabkan ketidakpahaman guru terkait alat-alat tersebut juga ketidak adaaan alat disekolah mereka.

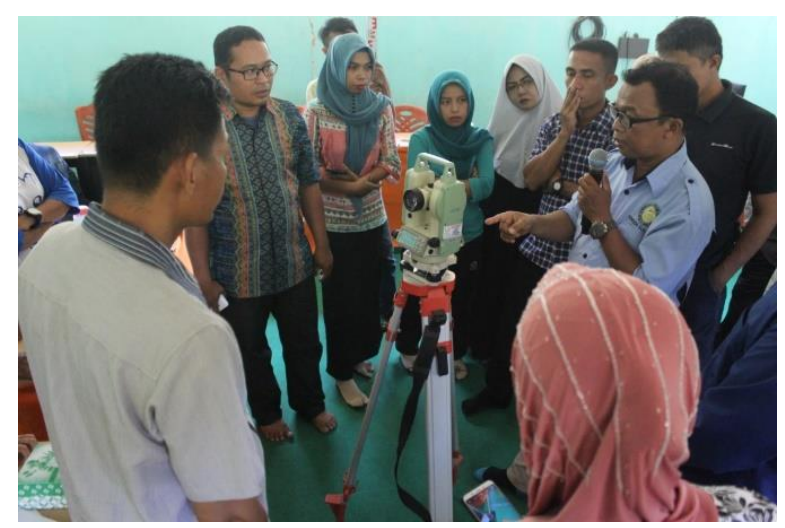

Gambar. 5.4 Pengenalan alat- alat praktikum geografi. 
Hasil identifikasi dari 20 guru terkait tingkat keterampilan dapat dilihat pada gambar 5.5. dari diagram tersebut terlihat bahwa, $60 \%$ dari guru yang hadir memiliki kemampuan dalam penggunaan alat yang rendah, hal ini dikarenakan mereka sama sekali blm pernah menggunakan alat-alat tersebut, baik sewaktu mereka menempuh kuliah maupun di tempat mereka saat ini. Sedangkan $30 \%$ sudah memahami sebagian alat yaitu GPS dan Kompas Geologi dan untuk theodolite sama sekali belum pernah digunakan. Sisanya yaitu $10 \%$ sudah pernah menggunakan semua alat yang dihadirkan di saat pelatihan, mereka ini merupakan guru honorer yang baru lulus dari prodi pendidikan geografi untad, sehingga sewaktu mereka kuliah mereka sudah menggunakan alat-alat ini pada saat praktikum.

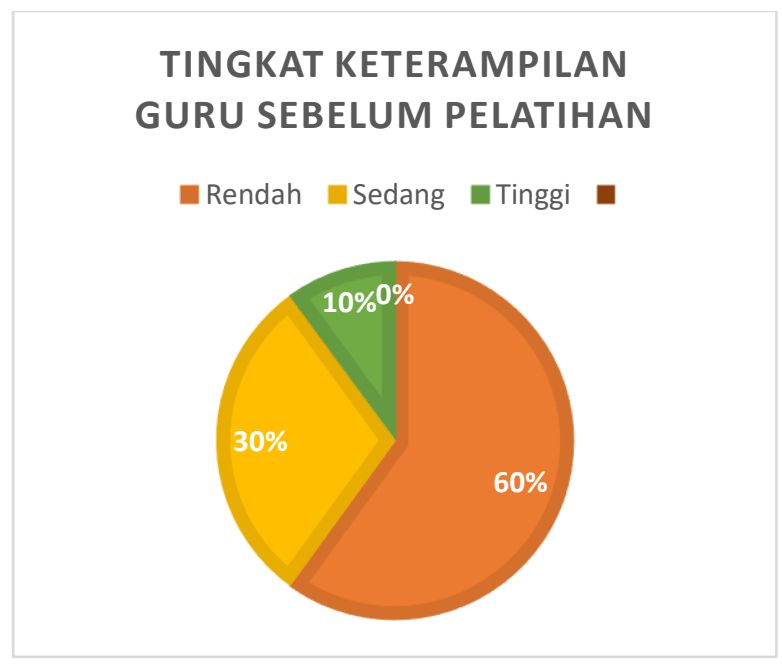

Gambar 5.4 Digram tingkat keterampilan guru dalam menggunakan alat-alat praktikum geografi sebelum pelatihan

Setelah kegiatan pelatihan selesai dilaksanakan kami selanjutnya melakukan evaluasi kembali terkait tingkat pengetahuan dan keterampilan mereka. Hasil yang diperoleh dapat dilihat pada Tabel 4.3 dan Gambar 5.5 dibawah ini.

Tabel 4.3 tingkat pengetahuan guru materi geografi setelah pelaksanaan pelatihan

\begin{tabular}{|c|l|c|}
\hline No & \multicolumn{1}{|c|}{ Materi } & Tingkat pengetahuan guru (\%) \\
\hline 1 & $\begin{array}{l}\text { Meteorologi dan } \\
\text { Klimatologi }\end{array}$ & $85 \%$ \\
\hline 2 & Oseanografi & $80 \%$ \\
\hline 3 & Geologi & $90 \%$ \\
\hline 4 & Kartografi & $60 \%$ \\
\hline 5 & Penginderaan Jauh & $60 \%$ \\
\hline 6 & Sumberdaya Alam & $85 \%$ \\
\hline
\end{tabular}




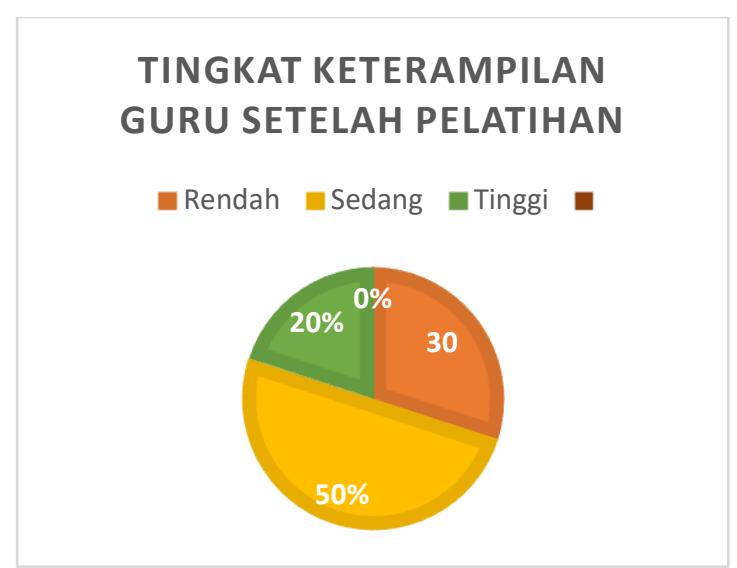

Gambar 5.4 Digram tingkat keterampilan guru dalam menggunakan alat-alat praktikum geografi setelah pelatihan

Hasil yang diperoleh menunjukkan kegiatan pelatihan ini memberikan manfaat yang besar bagi peningkatan pengetahuan dan keterampilan mereka. Dari hasil yang diperoleh terkhusus materi kartografi dan Penginderaan Jauh mengalami peningkatan 20\% dan 15\%, sedangkan keterampilan dan penggunaan alat tinggal $30 \%$ lagi guru yang belum mengerti dikarenakan alat yang dibawa kemarin harus digunakan secara bergantian oleh guru, sehingga beberapa guru tersebut belum sempat mempraktekan secara langsung penggunaan alat tersebut.

\section{SIMPULAN}

Berdasarkan hasil yang diperoleh maka dapat disimpulkan pada kegiatan pengabdian ini. Sebagian besar guru geografi SMA di Kabupaten Donggala telah mampu. mampu menambah pemahaman mereka terakait materi-materi yang dianggap susah, guru sudah mengetahui trik dalam menjawab soal-soal olimpiade serta guru telah mampu menggunakan alat-alat geografi.

\section{UCAPAN TERIMAKASIH}

Terima kasih kepada pihak KEMENRISTEKDIKTI yang telah memberikan dana hibah pengabdiannya kepada kami sehingga dapat melatih para guru-guru geografi di Kabupaten Donggala, khususnya dalam peningkatan pemahaman keilmuan mereka dan hasil akhirnya dapat memberikan pengaruh yang baik kepada siswa-siswa SMA di Kabupaten Donggala. 


\section{DAFTAR PUSTAKA}

Bafadal, Ibrahim. 2005. Pengelolaan Perpustakaan Sekolah. Jakarta: Bumi Aksara

Bintarto, R. 1991. Metode Analisa Geografi. Jakarta : LP3ES

Dj YR, Rosyad S, Muhtarom A. Determination of Development of Small Micro Business that Enforces Deket Village, Lamongan Indonesia District. Int J Res Manag Econ Commer. 2019;09(6):27-29.

Makmun, Syamsuddin. 2007. Psikologi Kependidikan. Bandung: Remaja

Muhtarom, Abid \& Tri Haryanto NI. Analysis of Agricultural Food Crop Productivity Planning District-District in East Java Province of Indonesia with A Non-Parametric Approach. MediaTrend. 2019;14(1):49-56.

Muhtarom A. PERANAN LEMBAGA PEMBERDAYAAN MASYARAKAT (LPM) DALAM PEMBANGUNAN DI DESA DI KABUPATEN LAMONGAN. $J$ Penelit Ekon dan Akunt. 2016;1(3):181-204.

Mujiani, N, M. 2017. Pelatihan Pembuatan Alat Peraga Ilmu Pengetahuan BumiAntariksa bagi Kelompok Guru SMP dan SMA Lab. UndikshaSingaraja. International Journal of Community Service LearningVolume 2, Number 1, 2018, pp. 1-9

Noehi Nasution. 1998. Materi Pokok Psikologi Pendidikan. Jakarta: direktorat Jenderal Pembinaan Kelembagaan Agama Islam dan Universitas Terbuka

Notoatmodjo, Soekidjo. 2009. Pengembangan Sumber Daya Manusia. Jakarta: PT. Rineka Cipta

Nurmala, B \& Erika I. 2009. Penggunaan Media Sederhana Dalam Penerapan Prinsip Korologi Pada Materi Tenaga Endogen Di Kelas Vii Smp Swasta Budi Agung Kecamatan Medan Marelan. Jurnal Geografi Vo.1 2 No. 2 Agustus 2010

Tilaar, A.R. 2002. Membenahi Pendidikan Nasional. Jakarta: Rineka Cipta. 